\title{
Early interventions to prevent retinal vasculopathy in diabetes: a review
}

This article was published in the following Dove Press journal:

Clinical Optometry

3I August 2015

Number of times this article has been viewed

\section{Wendy W Harrison Vladimir Yevseyenkov}

Arizona College of Optometry, Midwestern University, Glendale, AZ, USA

Correspondence: Wendy W Harrison Arizona College of Optometry, Midwestern University, 19555 N 59th Avenue, Glendale, AZ 85308, USA

$\mathrm{Tel}+\mathrm{I} 6235723907$

Fax + I 623572 39|I

Email wharri@midwestern.edu

\begin{abstract}
Diabetic eye disease is a public health concern in all areas of the world as a leading cause of blindness in the working aged to elderly populations. Diabetes damages the lining of the microvasculature throughout the body through prolonged exposure to hyperglycemic conditions. The ocular changes are progressive with very little recourse for improvement once damage begins. Current treatments for the eye focus mainly on the late stages of the disease when neovascularization or edema threatens sight. Early interventions for diabetic vasculopathy involve metabolic therapy to improve blood glucose and blood pressure control. Technology improvements have a large part to play in advancing diagnosis of diabetic eye disease. These new technologies offer both structural and functional means for assessment of retinal health. This review focuses on current treatments for diabetic eye disease at all stages with an emphasis on new and early interventions. It also details established and emerging technologies used for earlier detection of diabetic eye disease, which is vital to the development and approval of much needed treatments targeted at earlier stages of diabetic retinopathy. Possible future treatments should be aimed to prevent retinal vasculopathy from progressing. This review will explore current research on this topic and what is needed moving forward.
\end{abstract}

Keywords: diabetes, diabetic retinopathy, vascular disease

\section{Introduction}

Over the past several decades, there has been a tremendous effort to increase awareness surrounding diabetes mellitus (DM) and diabetic eye disease. Diabetes is a worldwide public health issue with a staggering 382 million cases. ${ }^{1}$ Many of these patients are undiagnosed, and the cases continue to increase at epidemic rates. Diabetes is an increasing cause of morbidity and mortality. ${ }^{2}$ The systems affected first include both neural and microvasculature of the kidneys, extremities, and eyes. Diabetic eye disease is present in $30 \%$ of those people with diabetes. ${ }^{3}$ In the USA, diabetes is the leading cause of non-traumatic limb amputation, kidney failure, and a leading cause of blindness. ${ }^{4-6}$ Early intervention is key in preventing these complications, which affect quality of life.

Diabetes is currently defined as an elevated fasting blood glucose level or an elevated serum hemoglobin $\mathrm{A}_{1} \mathrm{c}\left(\mathrm{HbA}_{1} \mathrm{c}\right)$ level. The inclusion of $\mathrm{HbA}_{1} \mathrm{c}$ as a diagnostic criterion is relatively new compared to blood glucose values. It was added as a criterion to the 2011 World Health Organization report. ${ }^{7}$ The American Diabetes Association indicates that an $\mathrm{HbA}_{1} \mathrm{c}$ over $6.5 \%$ and/or a fasting plasma glucose over $126 \mathrm{mg} / \mathrm{dL}$ are diagnostic of the disease. Although less commonly used, a 2-hour oral glucose tolerance over $200 \mathrm{mg} / \mathrm{dL}$ and/or a random plasma glucose over $200 \mathrm{mg} / \mathrm{dL}$ are also diagnostic. ${ }^{8}$ 
The symptoms at initial diagnosis vary widely but thirst and increased urination are among the most common. Sadly, many patients do not seek treatment for initial symptoms, leading to complications already being present at the time of diagnosis. ${ }^{8}$

It is well known that there are many types of diabetes. All types have the above diagnostic criterion in common, but it is important to note that beyond that they are very different diseases. This report will focus on the most common types of diabetes, type I and type II. Type II diabetes accounts for most of the cases of the disease ( $-90 \%-95 \%){ }^{8}$ It is commonly associated with many co-morbidities which affect ocular health in addition to hyperglycemia, making it a multifaceted disease to care for and monitor. It is estimated that only $14 \%$ of those with type II diabetes do not have an important co-morbidity, ${ }^{9}$ such as obesity, hypertension, hyperinsulinemia, and hyperlipidema. Type I diabetes is an autoimmune disorder resulting in the loss of the body's ability to produce insulin. ${ }^{8}$ Type I diabetes rarely includes the co-morbidities of type II diabetes and is always treated with insulin. Type II diabetes has a wider variety of treatment options.

\section{Pathophysiology and mechanisms leading to vascular damage in the eye}

Diabetes can be generally classified as a disease of the capillaries. After prolonged hyperglycemia, the vascular endothelial cells are damaged through one of many mechanisms soon described. This leads to thickening of the capillary basement membrane thereby preventing pericytes from being in contact with endothelial cells. ${ }^{10}$ Pericytes are the cells which are imbedded in the basement membrane of the blood vessels and help control the blood barriers. Drop out of the pericytes, which along with endothelial cells comprise the lining of the capillaries ensues, thus leading to increased leakage potential and breakdown of blood-retina barrier. Additionally, focal loss of the pericytes leads to bulging of the capillaries and microaneurysm formation.

The underlying pathophysiology of diabetic retinopathy (DR) and diabetic eye disease is multifactorial; thus far no single pathologic mechanism has been identified. Chronic hyperglycemia is the root cause and has a very strong relationship in developing DR. ${ }^{11,12}$ The main effect of hyperglycemia as it relates to DR is its ability to elicit pathological changes on vascular endothelium. ${ }^{13}$ Several interdependent metabolic mechanisms have been implicated through which hyperglycemia has an effect on vascular endothelium. These mechanisms include activation of protein kinase $\mathrm{C},{ }^{14}$ increased polyol, ${ }^{15}$ oxidative stress, ${ }^{16}$ up-regulation of vascular endothelial growth factors (VEGF), ${ }^{17}$ creation of advanced glycation end products, ${ }^{18}$ activation of the renin angiotensin system, ${ }^{19}$ and elevated prostaglandins. Platelets also, through a method of adhesion, secretion, and aggregation, alter the basement membrane of cell walls. ${ }^{20}$ Furthermore, chronic inflammation leads to leukostasis, which is clumping of the leukocytes. ${ }^{21}$ There are multiple other mechanisms, but it is vascular endothelial dysfunction that is at the center of all the mechanisms.

As the systemic and ocular components of the disease process progress, extra glucose in the body is converted to sorbital which does not have the ability to diffuse out of cells. This creates osmotic imbalance that leads to further weakening of the retinal capillaries walls, leading them to burst and causing dot and blot hemorrhages. ${ }^{22}$ This abnormal leakage leads to an increase in oncotic forces. This draws more fluid into the extravascular space, causing damage to the vascular endothelium composing inner retinal barrier. ${ }^{23}$ To summarize, tight junctions of the capillary endothelium are broken due to splitting of the pericytes leading to bulging of the capillaries. At the same time, the lumen constricts resulting in loss of capillaries that in turn results in retinal hypoxia and ischemia. In response to prolonged hypoxia, VEGF is released and triggers neovascularization, with new vessels being fenestrated, thus leading to more bleeding. ${ }^{10}$ Neovascularization leads to proliferation of the glial tissue resulting in fibrosis, which in turn can lead to traction of the vitreous. These end stage complications, neovascularization, traction, and edema, can lead to serious vision loss. ${ }^{24}$

\section{Diabetes in the eye and early diabetic vasculopathy}

In the eye, changes from diabetes are extensive and typically progressive. For the purposes of this paper, we will focus on diabetic effect on the retina. The most significant risk factor for developing DR is the length of time a patient has had DM. ${ }^{25}$ If a patient with type I DM has DM for 5-10 years, there is a $27 \%$ chance of developing DR; $71 \%$ if longer than 10 years, and $95 \%$ if longer than 30 years. For patients with type II diabetes for $11-13$ years, there is a $23 \%$ chance and if longer than 15 years there is a $60 \%$ chance of developing DR. ${ }^{25}$ This data means that progression of diabetes to diabetic eye disease is an expected finding over time. The timeline of appearance of diabetic changes varies with a wide variety of factors. Examples of important factors include length of the disease, glycemic and cholesterol levels just to name a few.

Figure 1 highlights the progression of diabetic eye disease through the various clinical stages. As stated earlier, the first 
visible retinal change is the formation of retinal microaneurysms (Figure 1A, yellow arrow). As evidenced from Figure $1 \mathrm{~B}$, they are not always visible with standard fundus evaluation but are easily viewed upon performing fluorescein angiography (FA). Later sections of this report will detail all the early diagnosis techniques available including FA. Dot (Figure 1C, red arrow) and blot (Figure 1C, yellow arrow) hemorrhages that result from ruptured microaneurysms form in the inner nuclear or outer plexiform layers and are the first visible signs of DR upon a dilated retinal eye examination Venus congestive
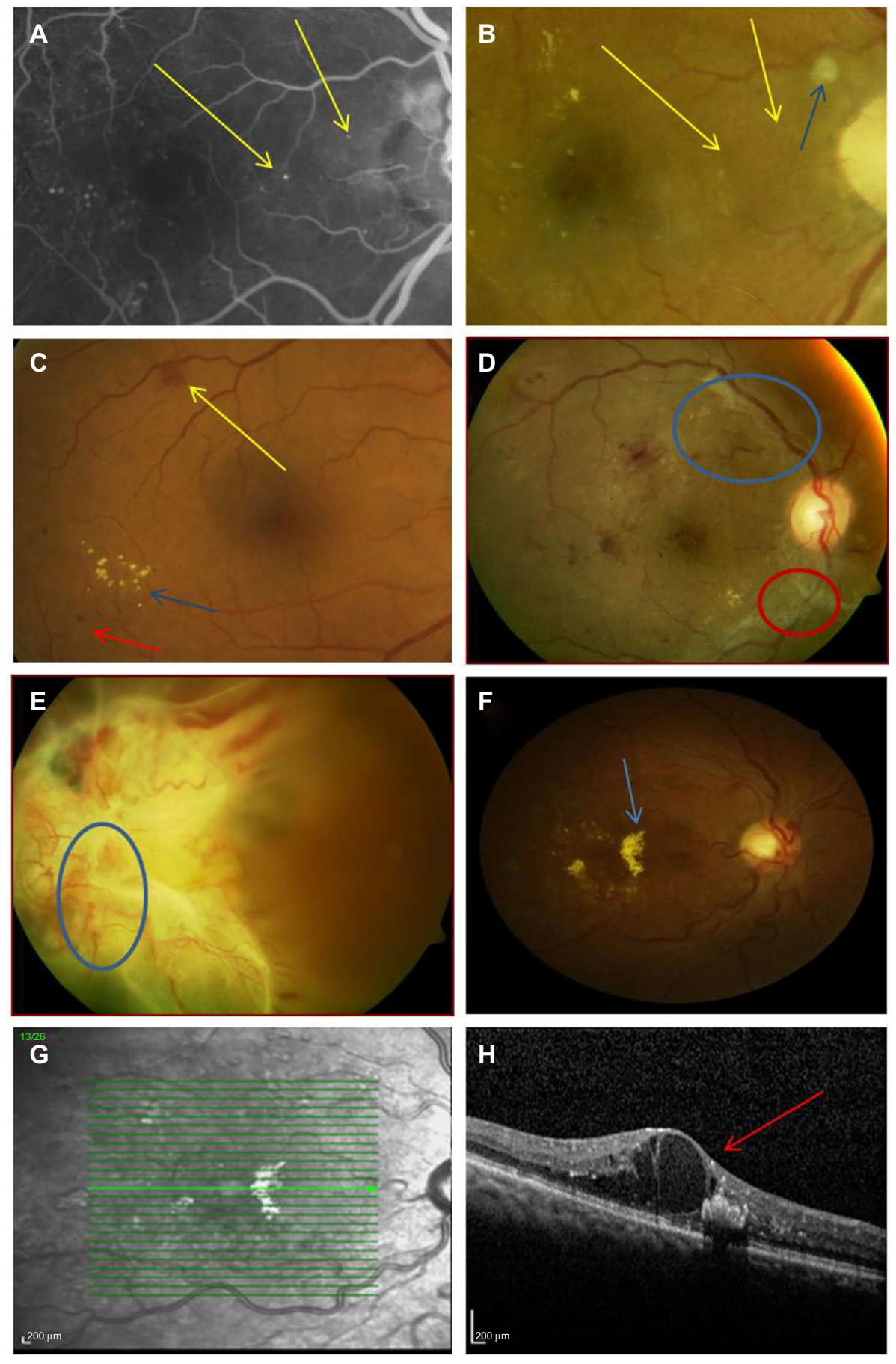

Figure I Retinal signs of diabetic retinopathy

Notes: (A) Fluorescein Angiography (FA) image of Figure IB, on FA image microaneurysms are readily observed (yellow arrow). (B) Moderate Diabetic retinopathy with exudates in the peri-macula region and no signs of microaneurysms, blue arrow is indicating a cotton wool spot. (C) Moderate diabetic retinopathy with dot (red arrow), blot (yellow arrow) and exudates (blue arrow) present in the posterior pole. (D) Proliferative Diabetic Retinopathy with infarcted neovascularization (red circle) and intraretinal microvascular abnormalities (Blue circle). (E) Tractional Retinal Detachment with proliferative diabetic retinopathy and vitreous hemorrhage, infarcted neo is marked by blue circle. (F) Mild Diabetic retinopathy with clinically significant macula edema, with exudate (blue arrow). (G) Optical coherence image of Figure IF, showing the exact location of the scan in Figure IH. (H) The scan line from Figure IG showing fluid accumulation in the outer plexiform layer of the retina (red arrow), indicating clinically significant macula edema. 
disease also often presents at this stage. The next phase of DR is when accumulated lipids start to leak from microaneurysms forming exudates (Figure 1B, yellow arrow; Figure 1C, blue arrow; and Figure 1F, blue arrow). Formation of cotton wool spots, which is a sign of focal retinal ischemia, is also quite common (Figure 1B, blue arrow). After prolonged cycles of hypoxia-normoxia and therefore constant dilation/constriction of the lumen due to vascular autoregulation, the vessels can develop tortuosity or can form venous beading. Venous beading is a very strong predictor of progression to neovascular or proliferative DR (PDR). After prolonged non-perfusion, retinal vessels can also respond by creating intraretinal shunting through the pre-existing capillary bed and form intraretinal microvascular abnormalities, which acts as a germination bed for neovascularization (Figure 1D, blue circle). In one of the final stages of DR development, new blood vessels which are fenestrated are formed (Figure 1E, blue circle and Figure 1D, red circle). This can progress to proliferation of the glial cell alongside endothelial cells resulting in fibrosis and tractional retinal detachment (Figure 1E, entire picture). ${ }^{26}$

Diabetic macula edema is the number one cause of vision reduction in DR and can take place at any stage of DR. Prior to the advent of optical coherence tomography (OCT), it was often quite difficult to tell if clinically significant macula edema (CSME) was present, but is easily detectable now with this technology (Figures $1 \mathrm{G}$ and $\mathrm{H}$ are an OCT image of Figure 1E, CSME is shown with a red arrow). CSME is defined by the Early Treatment of Diabetic Retinopathy Study (ETDRS): 1) Any retinal thickening within $500 \mu \mathrm{m}$ (one-third disc diameters) of the center of the macula. 2) Hard exudates within $500 \mu \mathrm{m}$ of the center of the macula with adjacent retinal thickening. 3) Retinal thickening at least 1 disc area in size, any part of which is within 1 disc diameter of the center of the macula. ${ }^{27}$

\section{Current treatments for diabetic eye disease}

The treatments available for the treatment of diabetic eye disease include metabolic control or changes in blood glucose and blood pressure levels, laser photocoagulation, intravitreal injections, and surgical care. Of the available treatments, three are aimed at late stage complications and only the first is aimed at early levels of retinopathy.

Currently, metabolic control is the number one intervention for delay of retinal vasculopathy. Intensive blood glucose control $\left(\mathrm{HbA}_{1} \mathrm{c} \leq 6 \%\right)$ in patients with type I diabetes was able to reduce rates of development of retinopathy by $54 \%$ in patients with some level retinopathy at baseline and up to $76 \%$ in patients if with no retinopathy at baseline. ${ }^{12}$ For patients with type II diabetes, tight blood glucose control and tight blood pressure control were able to reduce rates of progression of microvascular complications by $25 \%$ and $34 \%$, respectively. ${ }^{28}$ Tight cholesterol control has also been implicated in playing an important role in developing diabetic complications. ${ }^{29}$ Patient education by eye care professionals and primary care providers on the importance of tight glucose, blood pressure and cholesterol control has become standard of care in diabetes management and is easily one of the most important early intervention techniques in preventing development of DR.

The current standard of care treatment for PDR remains panretinal photocoagulation (PRP) laser therapy. This treatment was validated by the Diabetic Retinopathy Study in the mid-1970s and still remains the standard of care for PDR. ${ }^{30}$ ETDRS showed that preventative PRP is not indicated. It also established a standard of care for treatment of CSME as focal laser photocoagulation, which was able to reduce the risk of vision loss in patients with macula edema. Thus, a referral to a retinologist for an evaluation whether to perform the procedure is indicated in all cases of CSME independent of vision loss. ${ }^{31}$

There have been a number of studies trying to find better treatments for CSME, as the primary objective of focal laser photocoagulation is not to improve vision loss, but to prevent further loss of vision. Intravitreal steroid injections (IVTA) and implants have been tried extensively. However, the intravitreal steroid injection study (ISIS-DME) and the Diabetic Retinopathy Clinical Research Network have found IVTA for diabetic macula edema to have high complication rates compared to focal laser photocoagulation without longterm improvement in visual outcomes in all forms. ${ }^{32,33}$ To improve the safety profile of the IVTA injection, sustainedrelease drug delivery system such as OZURDEX (dexamethasone implant; Allergan, Inc., Irvine, CA, USA) have been trialed. ${ }^{34}$ Also trialed previously are extended release non-biodegradable steroid implants (Retisert fluocinolone acetonide intravitreal implant; Bausch and Lomb, Rochester, NY, USA), ${ }^{35}$ but the outcome of the these implants remained the same as IVTA.

Recently, the DA-VINCI study group (VEGF Trap-Eye in patients with diabetic macular edema) examined intravitreal anti-VEGF injections and found better primary outcomes of improved retinal thickness and improved acuity at all time periods up to 24 months compared to focal laser. ${ }^{36}$ In the most recent Diabetic Retinopathy Clinical Research Network report (2015), researchers compared the effectiveness of 
intravitreal aflibercept, bevacizumab, or ranibizumab. It was shown that all were able to improve macula edema equally for up to year if vision loss was mild to moderate, but in the most severe eyes aflibercept (Eylea; Regeneron, Tarrytown, NY, USA) was shown to be superior to the other anti-VEGF medications. ${ }^{37}$ Intravitreal anti-VEGF injections are becoming the first line of treatment for diabetic macular edema. This is due to the fact that they have the ability to improve vision rather than simply prevent further vision loss unlike focal laser photocoagulation and their superior safety profile compared to the intravitreal steroid injections. The biggest concern for the anti-VEGF treatments is that they do not have a prolonged effect and must be re-administered every 4-6 weeks for the duration of the disease. In cases when microaneurysms leak exudative material and form circinate retinopathy, anti-VEGF injections are the standard of care for treatment as focal grid laser cannot penetrate lipid-laden exudates. If microaneurysms leak on angiography, focal photocoagulation remains standard of care, but it is becoming very popular to utilize combination focal photocoagulation alongside anti-VEGF to treat edema.

\section{Early detection methods for diabetic eye disease}

It has been shown that early detection of diabetic eye disease is beneficial in reducing blindness. ${ }^{38}$ Early diagnosis usually comes with the recommendation for metabolic therapy discussed earlier. The combination of early detection along with metabolic therapy is currently the best intervention for reducing vasculopathy in diabetes. To this end, many newer studies focus extensively on the use of technologies to identify those with diabetic eye disease sooner. Features of the structure and function of the retina may be able to indicate when a patient is at higher risk for developing more serious diabetic eye disease in the future. Structural measures of diabetic change include fundus examination, angiography, OCT, and adaptive optics (AO) imaging. Functional measures, which are often more sensitive for early change, include psychophysical tests such as contrast sensitivity, color vision, and multifocal electroretinograms (mfERGs). All of these technologies, new and old, will be evaluated for their role in identification of early diabetic eye disease. The right combination of all of these tests may be the key to prevention of future vision loss.

\section{Fundus examination and photography}

A thorough fundus examination is the hallmark and gold standard of diabetic eye care. The Center for Disease
Control, ophthalmological, optometric, and diabetic associations are all in agreement that every patient with diabetes should receive annual dilated eye examinations. ${ }^{39}$ Unfortunately, only $50 \%-70 \%$ of patients with diabetes receive an annual dilated eye examination. ${ }^{40}$ Educating patients about the importance of yearly dilated eye examinations is one of the earliest intervention techniques in preventing retinal vascular disease.

DR is the most common factor evaluated during these examinations and has been graded on the same scale in the USA since the ETDRS. ${ }^{41,42}$ Multiple studies have validated this grading scale to be very consistent between eye care professionals. ${ }^{43-45}$ ETDRS also established follow-up guidelines depending on the level of DR: 1) DM without DR or mild non-proliferative DR (NPDR) (microaneurysm and hemorrhages in one quadrant of the eye) follow-up in 12 months; 2) moderate NPDR (hemorrhages and microaneurysm or exudates in more than one quadrant) follow-up in 6 months; 3) severe NPDR (4-2-1 rule, microaneurysm or hemorrhages in all four quadrants, venous beading in two quadrants, or intraretinal microvascular abnormalities vasculopathy in one quadrant) follow-up in 3 months; and 4) PDR requires an urgent referral for treatment. The presence of CSME at any stage of DR, independent of acuity also requires an urgent referral to a retinologist. ${ }^{42}$

Fundus photography is often performed in conjunction with dilated fundus examination and is a widespread technology worldwide. The ETDRS was first to comment on the relationship between the two, ${ }^{46}$ and many studies have followed suit. The results of these studies are mixed; many find that photography is an important adjunct to fundus examination for the monitoring of retinopathy. However, others find it to be less crucial, often depending on the skill level of the examiner. The studies that support the use of photography cite that subtle early signs of retinopathy such as microaneurysms are most likely to be missed by fundus examination alone. This indicates that a photograph may help aid in the diagnosis of very early DR more so than later stages. ${ }^{47}$

The use of photography has expanded beyond a standard office visit with the use of telemedicine programs. Telemedicine programs employ the strategy of evaluating lower risk diabetic patients every one to two years with fundus photograph(s) graded by an outside provider and in so doing frequently substitute the photography for the dilated fundus examination. This allows patients to have greater access to diabetic eye care and can reduce costs, but is not without its own risks and benefits. On the positive side, the more frequently patients are screened, the lower their risk of 
complications. However, concerns remain in identifying the number of photographs needed and who should grade those photographs. A recent review and meta-analysis of telemedicine in the British Journal of Ophthalmology ${ }^{48}$ highlights that telemedicine diabetes programs have excellent sensitivity and specificity for the detection of NPDR especially when the patient is dilated and the images are captured with a wide field camera. The specificity of the studies combined was $90 \%$, indicating that correctly identifying those with healthy retinas seems to be feasible. The American Academy of Ophthalmology does not recommend substituting a single field photo for a fundus examination due to the rate of under diagnosis of diabetic eye disease. ${ }^{49}$ Further concerns surround who should grade the images. It is clear that ideally this should be a trained eye care professional; however, recent studies have also evaluated grading by other sources with good results. Brady et al showed that crowd sourcing fundus grading might have potential. ${ }^{50}$ It is certain that these programs and this technology will continue to expand and develop, hopefully to the advantage of increasing screening among patients who need it most.

There is a great deal of research focusing on vessel changes in the fundus, not just the DR, to give information about early diabetic eye disease. This can be evaluated in both the context of a fundus examination as well as within a telemedicine program. Venous beading was discussed earlier in this report. Additionally, many studies have shown changes in the arterioles and the arteriovenous ratio early in the disease process. Arteriole narrowing is one of the most consistent metrics between studies, ${ }^{51-54}$ which may be influenced by the many co-morbidities of type II diabetes. Vessel tortuosity has been shown to be associated with DR in some studies. The recent study by Weiler et $\mathrm{al}^{44}$ indicates that arteriole tortuosity is a more consistent and powerful indicator of diabetic eye disease than venous tortuosity and may be a good metric to consider in early disease evaluation. Computerized metrics for evaluating vessels may assist with these issues and are becoming more readily available. ${ }^{55}$

\section{Ultra wide field FA and fundus autofluorescence}

Ultra wide field FA offers a 200 degree of view of the fundus as part of a FA. It often utilizes scanning laser ophthalmoscope (SLO) technology and is superior at detecting capillary dropout and non-perfusion over the entire eye compared to tradition FA. Figure 1 has already demonstrated the benefits of a standard FA over traditional fundoscopy for viewing early microaneurysms. Capillary drop out and areas of non-perfusion are early vascular signs of diabetic change that come before the DR grading scale. FA itself is an older technology, but this wide field technology addition is newer and adds a layer to the fundus evaluation. FA is more invasive than traditional fundoscopy. It involves a systemic injection of fluorescein dye, which travels to the eye, but offers different information. Capillary non-perfusion and drop out are often present but under-diagnosed signs of early diabetic eye disease, and this technology aids with this early diagnosis. ${ }^{56}$ In comparison to the seven field ETDRS protocol, an ultra wide field FA has shown to demonstrate significantly more non-perfusion. ${ }^{57}$

Fundus autofluorescence is a technique that involves a fluorescent image of the fundus. The technique is less invasive than the angiography described above and takes advantage of the properties of the photoreceptors themselves. Fundus autofluorescence is becoming more widely used for many ocular diseases. It has been shown that quantifying the amount of fluorescence is correlated with visual acuity and thickness information in eyes with diabetic edema. ${ }^{58}$ The expansion of the technology to earlier stages of diabetes may continue to occur in the future.

\section{Optical coherence tomography}

Another way to evaluate retinal structure is OCT. This technology emerged in the early 1990s and now has become widespread and is available in many optometric and ophthalmologic practices. OCT has made a considerable impact on the diagnosis of all eye disease, including diabetic eye disease. An example of an OCT in diabetic eye disease is shown in Figure $1 \mathrm{G}$ and $1 \mathrm{H}$. The majority of the literature surrounding OCT in diabetes focuses on diabetic macular edema. In a recent Cochrane report (2015) on the use of OCT inedema, it was found to have a sensitivity of $78 \%$ and specificity of $86 \%$ for the detection of CSME. ${ }^{59}$ As CSME can occur at any stage of DR and decreases vision, it is of particular concern. The conclusions of that report are that OCT alone is not sensitive enough for diagnosis but that false positives resulting from the use of OCT are generally subclinical cases that will likely progress in the future. The report still recommends careful fundus examination as the standard moving forward.

The use of OCT for earlier changes is not as clear. Studies vary on the expected changes in the overall retina from early diabetic eye disease. It is clear from clinical practice experience and study results that early diabetic changes, even microaneurysms are visible on an OCT scan, given a high 
enough resolution and the correct slice through tissue. Several studies document a variety of microaneurysm appearances visible on OCT. For example, microaneurysms in OCT which lack of a ring sign may be more associated with swelling. ${ }^{60}$ Leaking microaneurysms have also been documented on OCT as focal regions of thickening that correlate with fluorescein angiograms. When evaluating the retina tissue as a whole and not in focal locations, some studies cite retinal thinning while others retinal thickening. The thinning is likely due to tissue loss (apoptosis) in early diabetes and retinal thickening from fluid leakage in the tissue. ${ }^{61,62}$ Several factors seem to be involved here including type of diabetes, duration and severity of disease, and other health modifiers such as blood pressure. Harrison et $\mathrm{al}^{63}$ noted that retinal thickness increases with diastolic blood pressure in patients with mild retinopathy but no edema. This change was absent in patients without retinopathy indicating these as confounders. It seems clear from this work that the integrity of the blood retinal barrier is an important factor in the amount of swelling. Other studies have also indicated this result that these measures can be very complex. ${ }^{64,65}$ Most studies which evaluate OCT in early diabetes and NPDR measure both the thickness of the nerve fiber layer and the overall retinal thickness. Some studies have shown that the sensitivity and specificity in early disease is not as high as it is for detecting diabetic macular edema. ${ }^{66}$ Thus at this time, full retinal thickness changes alone are not a good assessment for diabetic eye disease without more information on the patient such as duration, type of diabetes, and blood sugar information. However, it is certain that they are useful in the health evaluation and prevention of vasculopathy of individual patients followed over time. Certainly, more studies evaluating OCT in early diabetes are warranted and can be expected as the technology continues to improve.

Furthermore, OCT technology has recently been combined with angiography technology as OCT angiography. Research shows that this non-invasive method allows excellent detection of early signs of diabetes such as capillary drop out and also may transform the way we look at PDR detection. By having the ability to create three-dimensional vascular imaging, we are now able to discriminate vascular lesions from the adjacent tissues. In recent studies, it has been demonstrated that OCT vascular angiography was able to show hyperreflective lesions in the inner retinal layers indicating retinal neovascularization at the different stages of neovascularization. ${ }^{67}$ As it gains approval for use in the USA, it should become more widely used for early detection.

\section{Adaptive optics imaging}

AO technology for use in early diabetic eye disease is expanding rapidly. ${ }^{68}$ This technology crosses the border of being both structural and functional depending on its use. $\mathrm{AO}$ works by correcting the higher order aberrations of the eye, beyond sphere and cylinder, with a deformable mirror. ${ }^{69}$ It can be coupled with both an OCT or SLO. An AO-SLO has the capabilities to view blood vessels in detail and peripheral cones. The work of Tam et $\mathrm{al}^{70-72}$ uses AO-SLO to track the movement of blood in patients with and without diabetes. They confirmed AO-SLO as a viable technique for early diabetic changes and viewed changes in the avascular zone, blood cells, and photoreceptors in these patients. In addition, other groups have found early changes in diabetes using AO technology. This includes differences in velocity of blood movement in diabetic patients, ${ }^{73}$ differences in cone density between patients with and without type I diabetes, ${ }^{74}$ and fine alterations in the cellular walls of patients with diabetes. ${ }^{75}$ Since AO can be coupled with functional tests with success, ${ }^{76}$ this area of research should expand greatly in the future. At this point, these instruments are mostly available in research institutions, but commercially available models are emerging. Imaging the blood cells themselves allows for a new level in the quest to reduce the impact of diabetic vascular changes.

\section{Functional measures of diabetic changes}

For decades, clinicians have noticed differences in some psychophysical measures in diabetic patients early in the disease process. This has been well documented in the literature over time. These functional measures include tests such as contrast sensitivity, color vision, and low contrast acuity to name a few. Of these tests, the literature surrounding contrast sensitivity decreases is likely the strongest. Many publications highlight decreased contrast even before retinopathy is present. ${ }^{77-78}$ In addition, early within the process of diabetic eye disease color vision changes are well documented by a variety of sources. These changes worsen as diabetic eye disease progresses. ${ }^{79}$

\section{Multifocal electroretinography}

The mfERG is one test that has been shown to identify changes in the retina at very early stages in diabetes and may be the most sensitive test for early changes to date. The mfERG technology was developed in the early $1990 \mathrm{~s}^{80}$ and has since been used in the evaluation of many ocular neuropathy conditions, including diabetes. The mfERG tests the retinal function of $32-103$ retinal locations in parallel using 
a pseudorandom m-sequence of flickering hexagons. It is highly reproducible between instruments and over time. ${ }^{81}$ The waveform of the mfERG produces a trough and a peak at each tested retinal location. The timing to the peak is known as the implicit time and the height from the trough to the peak is known as the amplitude. The technique is described in detail in the references given.

Overall, the test is driven by cone bipolar neurons that reside in close approximation to the retinal capillaries. ${ }^{82}$ In diabetes, the predictive use of the mfERG relies on the nature of the tissue as both neural and vascular. Local ocular neuropathy occurs early before the development of DR. This has shown to be true for early retinal changes all the way through to retinal edema and can be measured but not fundoscopically viewed.

The earliest studies using the mfERG in diabetic patients appeared in the late 1990s. These studies have expanded over the last 20 years and have evaluated the retina locally and overall. ${ }^{83}$ More recently, the mfERG has been used with other factors as an excellent way to predict future eye disease when used in conjunction with other health factors. ${ }^{84}$ This is true in type I and type II diabetic patients of all ages. The Adams UC Berkeley research group has created predictive models in patients with and without retinopathy over 1-3 year periods. These had sensitivities and specificity for prediction of new sites of retinopathy in patient eyes ranging from the low $80 \mathrm{~s}$ to the high 90s depending on the other known factors and comorbidities. ${ }^{85}$ In the model of patients with no prior retinopathy, the $\mathrm{mfERG}$ was $80 \%$ sensitive and $74 \%$ specific for the prediction of future retinopathy at specific retinal locations. ${ }^{86}$ This number rose when evaluating patients with retinopathy at risk for edema (84\% sensitivity and $76 \%$ specificity). ${ }^{87}$ Studies in children and specific populations have yielded similar results with retinopathy and other factors of diabetic health, such as duration, being highly correlated with mfERG changes. ${ }^{88,89,90}$

Overall, mfERG implicit time appears to be a reliable and reproducible marker for future retinopathy that may be considered as a marker or surrogate endpoint for future studies. While this technology remains largely isolated to research institutions, it is available throughout the USA and many other countries. We also expect continued research in the area of mfERG, diabetes, and related factors.

\section{Conclusion and treatments on the horizon}

There is no shortage of research on new treatments for diabetes in general or diabetic eye disease. However, to date there are no ocular treatments specific for early stages of DR. Most ocular treatments still focus on the later stages of the disease. The newest treatments for diabetes itself hold promise for reducing the burden of ocular disease via the importance of improving metabolic control. Most new treatments are in the family of incritin memetics (glucagon like peptide 1 analogs) or dipeptidyl peptidase 4 inhibitors (gliptins). Incritins are a family of proteins that help the pancreas release more insulin, and dipeptidyl peptidase 4 , is an enzyme that keeps incritins from working well. When evaluating new treatments for diabetes, exenatide injection, pramlintide injection, and Sitagliptin are the most recent additions to the US market. ${ }^{91} \mathrm{~A}$ great deal of research currently continues to evaluate natural therapies such as chlorogenic acids as well as vaccine and transplant options. ${ }^{92}$

Moving forward, ocular focused treatments that act on earlier stages of diabetic eye disease are needed. Advances in technology have improved our ability to diagnose differences between the retinal health of patients with and without diabetes. At our fingertips, we have a variety of ways to evaluate the fundus for retinal vasculopathy. What is currently lagging behind are treatment options for those patients with identified changes that move beyond metabolic control and interventions for PDR and CSME.

\section{Acknowledgments}

The authors thank Danielle Weiler OD and Nathan Harrison for their thoughts and assistance in the editing of this manuscript.

\section{Disclosure}

The authors report no conflicts of interest in this work.

\section{References}

1. International Diabetes Federation. Key Findings Facts and Figures; 2014. Available from: http://www.idf.org/worlddiabetesday/toolkit/gp/ facts-figures.

2. Hogan P, Dall T, Nikolov P. Economic costs of diabetes in the US in 2002. Diabetes Care. 2003;26(3):917-932.

3. Yau JW, Rogers SL, Kawasaki R, et al. Global prevalence and major risk factors of diabetic retinopathy. Diabetes Care. 2012;35(3):556-564.

4. NLLIC Amputee Coalition. Diabetes and Lower Extremeities Fact Sheet; 2008. Available from: http://www.amputee-coalition.org/fact_sheets/ amp_stats_cause.pdf. Accessed December 15. 2014.

5. National Insititue of Diabetes and Digestive and Kidney Disease Clearing House. Kidney Disease of Diabetes; 2014. Available from: http://www. niddk.nih.gov/health-information/health-topics/kidney-disease/kidneydisease-of-diabetes/Pages/facts.aspx.

6. National Eye Institute. Diabetes Fact Sheet; 2012. Available from: https:// nei.nih.gov/health/diabetic/retinopathy.

7. World Health Organization. Use of Glycated Haemoglobin ( $\mathrm{Hb} A_{\mathrm{Il}}$ ) in the Diagnosis of Diabetes Mellitus; 2011. Available from: http://www. who.int/diabetes/publications/report-hba1c_2011.pdf.

8. American Diabetes Association. Diagnosis of diabetes. Available fromwww.diabetes.org; 2014. Accessed December 15, 2014. 
9. Suh DC, Choi IS, Plauschinat C, et al. Impact of comorbid conditions and race/ ethnicity on glycemic control among the US population with type 2 diabetes, 1988-1994 to 1999-2004. J Diabetes Compl. 2010; 24(6):382-391.

10. Cai J, Boulton M. The pathogenesis of diabetic retinopathy: old concepts and new questions. Eye (Lond). 2002;16(3):242-260.

11. White NH, Cleary PA, Dahms W, et al. Beneficial effects of intensive therapy of diabetes during adolescence: outcomes after the conclusion of the Diabetes Control and Complications Trial (DCCT). J Pediatr. 2001;139(6):804-812.

12. The DCCT Research Group. The effect of intensive treatment of diabetes on the development and progression of long-term complications in insulindependent diabetes mellitus. N Engl J Med. 1993;329:977-986.

13. Alder VA, Su EN, Yu DY, et al. Diabetic retinopathy: early functional changes. Clin Exp Pharmacol Physiol. 1997;24(9-10):785-788.

14. Ways D, Sheetz MJ. The role of protein kinase C in the development of the complications of diabetes. Vitam Horm. 2001;60:149-159.

15. Naruse K, Nakamura J, Hamada Y, et al. Aldose reductase inhibition prevents glucose-induced apoptosis in cultured bovine retinal microvascular pericytes. Exp Eye Res. 2000;71(3):309-315.

16. Gurler B, Vural H, Yilmaz N, et al. The role of oxidative stress in diabetic retinopathy. Eye (Lond). 2000;14(Pt 5):730-735.

17. Sone H, Deo BK, Kumagai AK. Enhancement of glucose transport by vascular endothelial growth factor in retinal endothelial cells. Invest Ophthalmol Vis Sci. 2000;41(7):1876-1884.

18. Chu J, Ali, Y. Diabetic retinopathy: a reivew. Drug Dev Res. 2008;69: $1-14$.

19. Tarr JM, Kaul K, Chopra M, et al. Pathophysiology of diabetic retinopathy. ISRN Ophthalmol. 2013;2013:343560.

20. Colwell JA, Halushka PV, Sarji K, et al. Altered platelet function in diabetes mellitus. Diabetes. 1976;25(2 Suppl):826-831.

21. Sayin N, Kara N, Pekel G. Ocular complications of diabetes mellitus. World J Diabetes. 2015;6(1):92-108.

22. Zhang W, Liu H, Al-Shabrawey M, et al. Inflammation and diabetic retinal microvascular complications. J Cardiovasc Dis Res. 2014;2(2): 96-103.

23. Singh R, Ramasamy K, Abraham C, et al. Diabetic retinopathy: an update. Indian J Ophthalmol. 2008;56(3):178-188.

24. Friedlander M. Fibrosis and diseases of the eye. J Clin Invest. 2007; 117(3):576-586.

25. Klein R, Klein BE, Moss SE, et al. The Wisconsin Epidemiologic Study of diabetic retinopathy. XIV. Ten-year incidence and progression of diabetic retinopathy. Arch Ophthalmol. 1994;112(9):1217-1228.

26. Wu L, Fernandez-Loaiza P, Sauma J, et al. Classification of diabetic retinopathy and diabetic macular edema. World J Diabetes. 2013;4(6): 290-294.

27. Photocoagulation for diabetic macular edema. Early treatment diabetic retinopathy study report number 1. Early Treatment Diabetic Retinopathy Study Research Group. Arch Ophthalmol. 1985;103(12):1796-1806.

28. Tight blood pressure control and risk of macrovascular and microvascular complications in type 2 diabetes: UKPDS 38. UK Prospective Diabetes Study Group. BMJ. 1998;317(7160):703-713.

29. Ueda H. Importance of serum cholesterol level in development of diabetic autonomic neuropathy. Diabetes Res Clin Pract. 1993;21(2-3):123.

30. The Diabetic Retinopathy Study Research Group. Preliminary report on effects of photocoagulation therapy. Am J Ophthalmol. 1976;81(4): 383-396.

31. Early Treatment Diabetic Retinopathy Study Research Group. Grading diabetic retinopathy from stereoscopic color fundus photographs - an extension of the modified Airlie House classification. ETDRS report number 10. Ophthalmology. 1991;98(5 Suppl):786-806.

32. Kim JE, Pollack JS, Miller DG, et al. ISIS-DME: a prospective, randomized, dose-escalation intravitreal steroid injection study for refractory diabetic macular edema. Retina. 2008;28(5):735-740.

33. Beck RW, Edwards AR, Aiello LP, et al. Three-year follow-up of a randomized trial comparing focal/grid photocoagulation and intravitreal triamcinolone for diabetic macular edema. Arch Ophthalmol. 2009; 127(3):245-251.
34. Rishi P, Rishi E, Kuniyal L, et al. Short-term results of intravitreal dexamethasone implant $\left(\mathrm{OZURDEX}{ }^{\circledR}\right)$ in treatment of recalcitrant diabetic macular edema: a case series. Oman J Ophthalmol. 2012;5(2):79-82.

35. Messenger WB, Beardsley RM, Flaxel CJ. Fluocinolone acetonide intravitreal implant for the treatment of diabetic macular edema. Drug Des Devel Ther. 2013;7:425-434.

36. Do DV, Schmidt-Erfurth U, Gonzalez VH, et al. The DA VINCI Study: phase 2 primary results of VEGF Trap-Eye in patients with diabetic macular edema. Ophthalmology. 2011;118(9):1819-1826.

37. Wells JA, Glassman AR, Ayala AR, et al. Aflibercept, bevacizumab, or ranibizumab for diabetic macular edema. N Engl J Med. 2015;372(13): 1193-1203.

38. Bandello F, Lattanzio R, Zucchiatti I, et al. Pathophysiology and treatment of diabetic retinopathy. Acta Diabetol. 2013;50(1):1-20.

39. American Diabetes Association. Eye Complications; 2013. Available from: http://www.diabetes.org/living-with-diabetes/complications/ eye-complications/.

40. Shea AM, Curtis LH, Hammill BG, et al. Resource use and costs associated with diabetic macular edema in elderly persons. Arch Ophthalmol. 2008;126(12):1748-1754.

41. Early Treatment Diabetic Retinopathy Study design and baseline patient characteristics. ETDRS report number 7. Ophthalmology. 1991; 98(5 Suppl):741-756.

42. Early Treatment Diabetic Retinopathy Study Research Group. Fundus photographic risk factors for progression of diabetic retinopathy. ETDRS report number 12. Ophthalmology. 1991;98(5 Suppl):823-833.

43. Ruamviboonsuk P, Teerasuwanajak K, Tiensuwan M, et al. Interobserver agreement in the interpretation of single-field digital fundus images for diabetic retinopathy screening. Ophthalmology. 2006;113(5): 826-832.

44. Weiler D, Engelke CB, Moore ALO, et al. Arteriole tortuoisty associated with diabetic retinopathy and cholesterol. Optom Vis Sci. 2015;92(3).

45. Patra S, Gomm EM, Macipe M, et al. Interobserver agreement between primary graders and an expert grader in the Bristol and Weston diabetic retinopathy screening programme: a quality assurance audit. Diabet Med. 2009;26(8):820-823.

46. Kinyoun J, Barton F, Fisher M, et al; The ETDRS Research Group. Detection of diabetic macular edema. Ophthalmoscopy versus photography - early treatment diabetic retinopathy study report number 5 . Ophthalmology. 1989;96(6):746-750; discussion 750-751.

47. Kinyoun JL, Martin DC, Fujimoto WY, et al. Ophthalmoscopy versus fundus photographs for detecting and grading diabetic retinopathy. Invest Ophthalmol Vis Sci. 1992;33(6):1888-1893.

48. Shi L, Wu H, Dong J, et al. Telemedicine for detecting diabetic retinopathy: a systematic review and meta-analysis. Br J Ophthalmol. doi:10.1136/bjophthalmol-2014-305631.

49. American Academy of Ophthalmology. Preferred Practice Pattern ${ }^{\circledR}$. Diabetic retinopathy. Available from: http://one.aao.org/CE/ PracticeGuidelines; 2008. Accessed December 15, 2014.

50. Brady CJ, Villanti AC, Pearson JL, et al. Rapid grading of fundus photographs for diabetic retinopathy using crowdsourcing. J Med Internet Res. 2014;16(10):e233.

51. Sun C, Wang JJ, Mackey DA, et al. Retinal vascular caliber: systemic, environmental, and genetic associations. Surv Ophthalmol. 2009;54(1): 74-95.

52. Jeganathan VS, Sabanayagam C, Tai ES, et al. Retinal vascular caliber and diabetes in a multiethnic Asian population. Microcirculation. 2009;16(6):534-543.

53. Kifley A, Wang JJ, Cugati S, et al. Retinal vascular caliber, diabetes, and retinopathy. Am J Ophthalmol. 2007;143(6):1024-1026.

54. Tikellis G, Wang JJ, Tapp R, et al. The relationship of retinal vascular calibre to diabetes and retinopathy: the Australian Diabetes, Obesity and Lifestyle (AusDiab) study. Diabetologia. 2007;50(11):2263-2271.

55. Knudtson MD, Lee KE, Hubbard LD, et al. Revised formulas for summarizing retinal vessel diameters. Curr Eye Res. 2003;27(3):143-149.

56. Suner I. Ultra-widefield fluorescein angiography in the diagnosis and management of diabetic retinopathy. Retina Today. 2010;(July/ August):56-58. 
57. Wessel MM, Aaker GD, Parlitsis G, et al. Ultra-wide-field angiography improves the detection and classification of diabetic retinopathy. Retina. 2014;32(4):785-791.

58. Yoshitake S, Murakami T, Uji A, et al. Clinical relevance of quantified fundus autofluorescence in diabetic macular oedema. Eye (Lond). Epub March 13, 2015

59. Virgili G, Menchini F, Casazza G, et al. Optical coherence tomography (OCT) for detection of macular oedema in patients with diabetic retinopathy. Cochrane Database System Rev. 2015;1:CD008081.

60. Horii T, Murakami T, Nishijima K, et al. Optical coherence tomographic characteristics of microaneurysms in diabetic retinopathy. Am J Ophthalmol. 2010;150(6):840-848.

61. Bronson-Castain KW, Bearse MA Jr, Neuville J, et al. Adolescents with Type 2 diabetes: early indications of focal retinal neuropathy, retinal thinning, and venular dilation. Retina. 2009;29(5):618-626.

62. Cabera DeBuc D, Somfal, GM. Early detection of retinal thickness changes in diabetes using optical coherence tomography. Med Sci Monit. 2010;16(3):15-21.

63. Harrison WW, Chang A, Cardenas MG, et al. Blood pressure, vessel caliber, and retinal thickness in diabetes. Optom Vis Sci. 2012;89(12): $1715-1720$

64. Sander B, Thornit DN, Colmorn L, et al. Progression of diabetic macular edema: correlation with blood retinal barrier permeability, retinal thickness, and retinal vessel diameter. Invest Ophthalmol Vis Sci. 2007;48(9):3983-3987.

65. Dhamdhere KP, Bearse MA Jr, Harrison W, et al. Associations between local retinal thickness and function in early diabetes. Invest Ophthalmol Vis Sci. 2012;53(10):6122-6128.

66. Sugimoto M, Sasoh M, Ido M, et al. Detection of early diabetic change with optical coherence tomography in type 2 diabetes mellitus patients without retinopathy. Ophthalmologica. Int J Ophthalmol. 2005;219(6):379-385.

67. Miura M, Hong YJ, Yasuno Y, et al. Three-dimensional vascular imaging of proliferative diabetic retinopathy by Doppler optical coherence tomography. Am J Ophthalmol. 2015;159(3):528-538.

68. Bek T. Fine structure in diabetic retinopathy lesions as observed by adaptive optics imaging. A qualitative study. Acta Ophthalmol. 2014; 92(8):753-758.

69. Porter J, Queener H, Lin J, et al. Adaptive Optics for Vision Science: Principles, Practices, Design and Applications. Wiley, Hoboken, NJ; 2006.

70. Tam J, Dhamdhere KP, Tiruveedhula P, et al. Disruption of the retinal parafoveal capillary network in type 2 diabetes before the onset of diabetic retinopathy. Invest Ophthalmol Vis Sci. 2011;52(12):9257-9266.

71. Tam J, Tiruveedhula P, Roorda A. Characterization of single-file flow through human retinal parafoveal capillaries using an adaptive optics scanning laser ophthalmoscope. Biomed Opt Express. 2011;2(4):781-793.

72. Tam J, Dhamdhere KP, Tiruveedhula P, et al. Subclinical capillary changes in non-proliferative diabetic retinopathy. Optom Vis Sci. 2012; 89(5):E692-E703.

73. Arichika S, Uji A, Murakami T, et al. Retinal hemorheologic characterization of early-stage diabetic retinopathy using adaptive optics scanning laser ophthalmoscopy. Invest Ophthalmol Vis Sci. 2014;55(12):8513-8522.
74. Lombardo M, Parravano M, Lombardo G, et al. Adaptive optics imaging of parafoveal cones in type 1 diabetes. Retina. 2014;34(3):546-557.

75. Chui TY, Gast TJ, Burns SA. Imaging of vascular wall fine structure in the human retina using adaptive optics scanning laser ophthalmoscopy. Invest Ophthalmol Vis Sci. 2013;54(10):7115-7124.

76. Rossi EA, Roorda A. The relationship between visual resolution and cone spacing in the human fovea. Nat Neurosci. 2010;13(2):156-157.

77. Della Sala S, Bertoni G, Somazzi L, Stubbe F, Wilkins AJ. Impaired contrast sensitivity in diabetic patients with and without retinopathy: a new technique for rapid assessment. Br J Ophthalmol. 1985;69(2): 136-142.

78. Dhamdhere KP, Schneck ME, Bearse MA Jr, et al. Assessment of macular function using the SKILL Card in adults with type 2 diabetes mellitus. Invest Ophthalmol Vis Sci. 2014;55(6):3368-3374.

79. Wolff BE, Bearse MA Jr, Schneck ME, et al. Color vision and neuroretinal function in diabetes. Doc Ophthalmol. 2015;130(2):131-139.

80. Sutter EE, Tran D. The field topography of ERG components in man -I. The photopic luminance response. Vision Res. 1992;32(3):433-446.

81. Harrison WW, Bearse MA Jr, Ng JS, et al. Reproducibility of the mfERG between instruments. Doc Ophthalmol. 2009;119(1):67-78.

82. Hood DC, Frishman LJ, Saszik S, et al. Retinal origins of the primate multifocal ERG: implications for the human response. Invest Ophthalmol Vis Sci. 2002;43(5):1673-1685.

83. Bearse MA Jr, Ozawa GY. Multifocal electroretinography in diabetic retinopathy and diabetic macular edema. Curr Diab Rep. 2014;14(9):526.

84. Bearse MA Jr, Adams AJ, Han Y, et al. A multifocal electroretinogram model predicting the development of diabetic retinopathy. Prog Retin Eye Res. 2006;25(5):425-448.

85. Ng JS, Bearse MA Jr, Schneck ME, et al. Local diabetic retinopathy prediction by multifocal ERG delays over 3 years. Invest Ophthalmol Vis Sci. 2008;49(4):1622-1628.

86. Harrison WW, Bearse MA Jr, Ng JS, et al. Multifocal electroretinograms predict onset of diabetic retinopathy in adult patients with diabetes. Invest Ophthalmol Vis Sci. 2011;52(2):772-777.

87. Harrison WW, Bearse MA Jr, Schneck ME, et al. Prediction, by retinal location, of the onset of diabetic edema in patients with nonproliferative diabetic retinopathy. Invest Ophthalmol Vis Sci. 2011;52(9): 6825-6831.

88. Tan W, Wright T, Dupuis A, et al. Localizing functional damage in the neural retina of adolescents and young adults with type 1 diabetes. Invest Ophthalmol Vis Sci. 2014;55(4):2432-2441.

89. Laron M, Bearse MA Jr, Bronson-Castain K, et al. Association between local neuroretinal function and control of adolescent type 1 diabetes. Invest Ophthalmol Vis Sci. 2012;53(11):7071-7076.

90. Adhikari P, Marasini S, Sah RP, et al. Multifocal electroretinogram responses in Nepalese diabetic patients without retinopathy. Doc Ophthalmol. 2014;129(1):39-46.

91. Joslin Center for Diabetes. Stay healthy with diabetes. Available from: http://www.joslin.org/info/Spotlight_on_New_Diabetes_Treatments. html; 2015. Accessed December 15, 2014.

92. Diabetes UK. Behind the Headlines. Available from: http://www.diabetes.org.uk/Research/Research-round-up; 2015. Accessed December 15, 2014.
Clinical Optometry

\section{Publish your work in this journal}

Clinical Optometry is an international, peer-reviewed, open access journal publishing original research, basic science, clinical and epidemiological studies, reviews and evaluations on clinical optometry. All aspects of patient care are addressed within the journal as well as the practice of optometry including economic and business analyses. Basic and clinical Submit your manuscript here: http://www.dovepress.com/clinical-optometry-journal

\section{Dovepress}

research papers are published that cover all aspects of optics, refraction and its application to the theory and practice of optometry. The manuscript management system is completely online and includes a very quick and fair peer-review system, which is all easy to use. Visit http://www.dovepress. com/testimonials.php to read real quotes from published authors. 